\title{
Experimental and Numerical Investigation of Air Radiation in Superorbital Expanding Flow
}

Han Wei $^{1}$ Richard G. Morgan ${ }^{1}$ Timothy J. McIntyre ${ }^{1}$ Aaron M. Brandis ${ }^{2}$ Christopher O. Johnston ${ }^{3}$

${ }^{1}$ Centre for Hypersonics, the University of Queensland ${ }^{2}$ AMA at NASA Ames Research Center ${ }^{3}$ NASA Langley Research Center

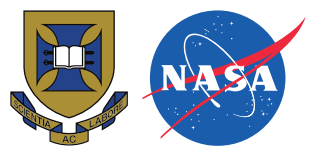

9th June 2017 


\section{Outline}

1 Introduction

2 Experimental Campaign

3 Numerical Simulation

4 Results and Analysis

- Flow Establishment

- VUV Spectra

5 Conclusions 


\section{Outline}

\section{Introduction}

2 Experimental Campaign

3 Numerical Simulation

4 Results and Analysis

- Flow Establishment

- VUV Spectra

5 Conclusions 


\section{Afterbody TPS}

Afterbody Heatshield:

- Cocooning the bulk of the vehicle surface

- Bearing large design uncertainty up to $300 \%^{[1]}$

Afterbody Radiative Heating:

- May be important for Superorbital re-entry: Mars return

- Found to be significant with state-of-the-art simulations ${ }^{[2]}$

- No discernible data recorded by afterbody radiometers of Fire II and Apollo 4

[1] Michael J. Wright, Frank S. Milos, and Phillippe Tran. "Afterbody Aeroheating Flight Data for Planetary Probe Thermal Protection System Design". In: Journal of Spacecraft and Rockets 43.5 (Sept. 2006), pp. 929-943.

[2] Christopher O. Johnston and Aaron M. Brandis. "Features of Afterbody Radiative Heating for Earth Entry". In: Journal of Spacecraft and Rockets 52.1 (2015), pp. 105-119. 


\section{Post-mission Analyses}

- Wright et al. ${ }^{[3]}$ achieved excellent agreement with Fire II forebody convective heating data, but the afterbody experimental data were a factor of two higher than the noncatalytic predictions

- Johnston and Brandis ${ }^{[4]}$ re-examined the FIRE II afterbody measurements and questioned the analysis of the radiometer data. Major sources of model uncertainties for afterbody radiation were identified: the rate coefficient for the three-body electron-ion recombination reaction, the escape factors on collisional-radiative modelling, and the impact of forebody ablation.

[3] Michael Wright, Mark Loomis, and Periklis Papadopoulos. "Aerothermal Analysis of the Project Fire II Afterbody Flow". In: Journal of Thermophysics and Heat Transfer 17.2 (2003), pp. 240-249.

[4] Christopher O. Johnston and Aaron M. Brandis. "Features of Afterbody Radiative Heating for Earth Entry". In: Journal of Spacecraft and Rockets 52.1 (2015), pp. 105-119. 
- Johnston and Panesi ${ }^{[5]}$ : treating nitrogen atoms of different grouped electronic levels as individual species in the flow field model, coupling radiative transition rates to the species continuity equations, adopting a ray-tracing approach in radiation transport calculation and developing a nonequilibrium model for $\mathrm{NO}$

- Lopez et al. ${ }^{[6]}$ improved the non-Boltzmann modelling of nitrogen by adopting a state-to-state description of grouped electronic states

[5] Christopher O. Johnston and Marco Panesi. "Advancements in Afterbody Radiative Heating Simulations for Earth Entry". In: 46th AIAA Thermophysics Conference. AIAA Aviation. American Institute of Aeronautics and Astronautics, June 13, 2016.

[6] Bruno Lopez, Christopher O. Johnston, and Marco Panesi. "Improved Non-Boltzmann Modeling for Nitrogen Atoms". In: 46th AIAA Thermophysics Conference. AIAA Aviation. American Institute of Aeronautics and Astronautics, June 10, 2016. 
- West et al. ${ }^{[7]}$ performed sensitivity analysis and uncertainty quantification of afterbody radiation for Stardust at peak afterbody radiative heating conditions. Four variables were found to contribute to nearly $95 \%$ of the uncertainty: the electronic-impact excitation rate for $\mathrm{N}$ between levels 2 and 5 and the rates of three chemical reactions that affect the number densities of $\mathrm{N}, \mathrm{N}^{+}, \mathrm{O}$ and $\mathrm{O}^{+}$.

- Validation data of afterbody radiation is in high demand, particularly in the VUV wavelength range

[7] Thomas K. West IV, Christopher O. Johnston, and Serhat Hosder. "Uncertainty and Sensitivity Analysis of Afterbody Radiative Heating Predictions for Earth Entry". In: 54th AIAA Aerospace Sciences Meeting. AIAA SciTech. American Institute of Aeronautics and Astronautics, Jan. 2, 2016. 


\section{Outline}

1 Introduction

2 Experimental Campaign

3 Numerical Simulation

4 Results and Analysis

- Flow Establishment

- VUV Spectra

5 Conclusions 


\section{Facility, Model and Flow Conditions}

\section{X2 Expansion Tunnel}

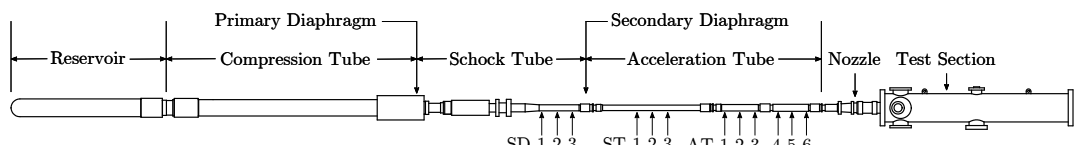

SD 123 ST 123 AT 123456

Test Model:

- 54 $4^{\circ}$ wedge: $25 \mathrm{~mm}$ tall and $100 \mathrm{~mm}$ wide

Flow Conditions:

\begin{tabular}{ccccc}
\hline \hline Condition & $\begin{array}{c}\text { Velocity } \\
(\mathrm{m} / \mathrm{s})\end{array}$ & $\begin{array}{c}\text { Static } \\
\text { Pressure }(\mathrm{Pa})\end{array}$ & $\begin{array}{c}\text { Static } \\
\text { Temperature }(\mathrm{K})\end{array}$ & $\begin{array}{c}\text { Stagnation } \\
\text { Enthalpy (MJ/kg) }\end{array}$ \\
\hline 1 & $9714 \pm 0.6 \%$ & $1308 \pm 8.8 \%$ & $2609 \pm 1.1 \%$ & $50.7 \pm 0.9 \%$ \\
2 & $10899 \pm 0.3 \%$ & $1523 \pm 6.8 \%$ & $2713 \pm 1.0 \%$ & $63.4 \pm 0.7 \%$ \\
3 & $11837 \pm 1.0 \%$ & $843 \pm 10 \%$ & $2892 \pm 0.8 \%$ & $75.4 \pm 2.0 \%$ \\
\hline \hline
\end{tabular}




\section{The Spectral Measurements}

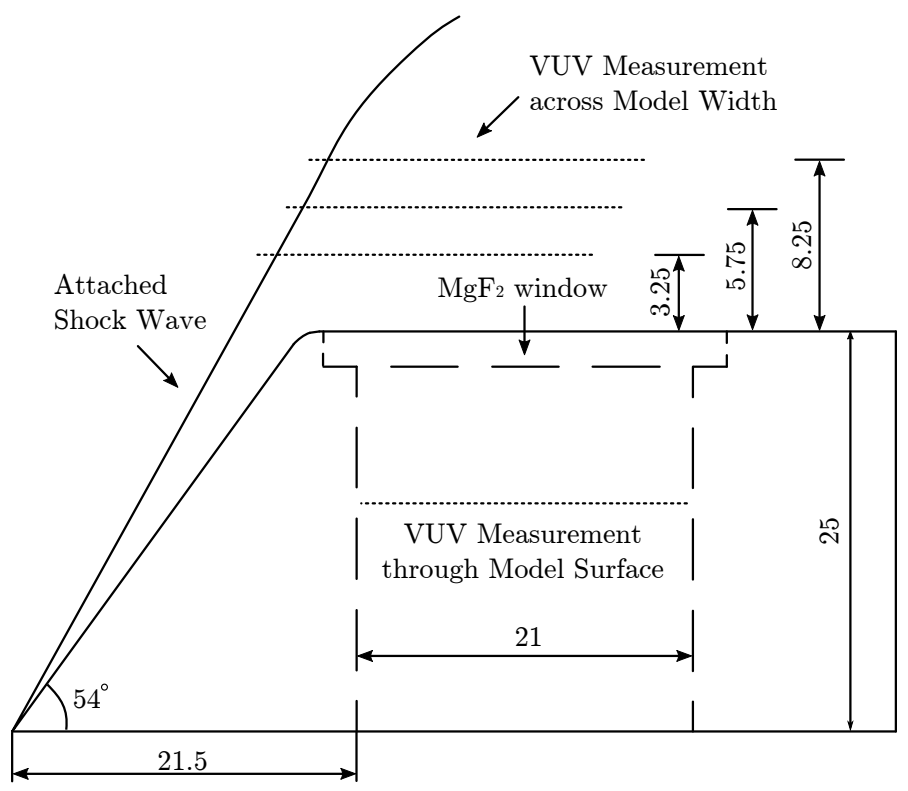




\section{Aross-Wedge Measurement}

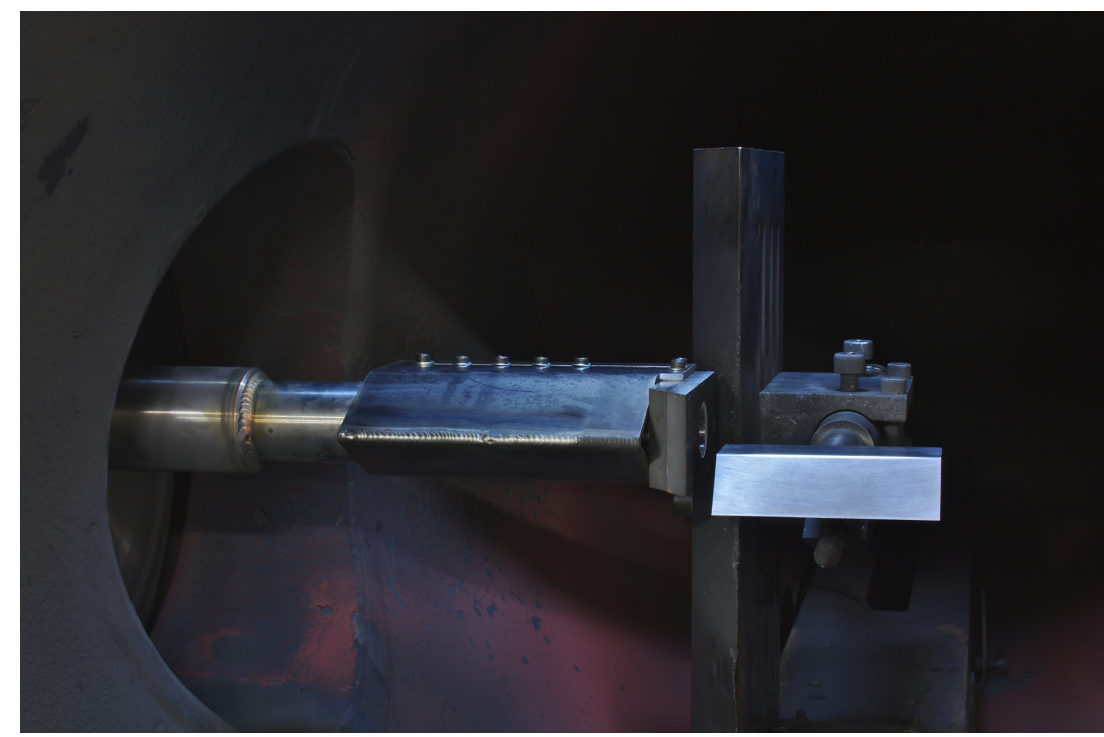




\section{Through-Wedge Measurement}

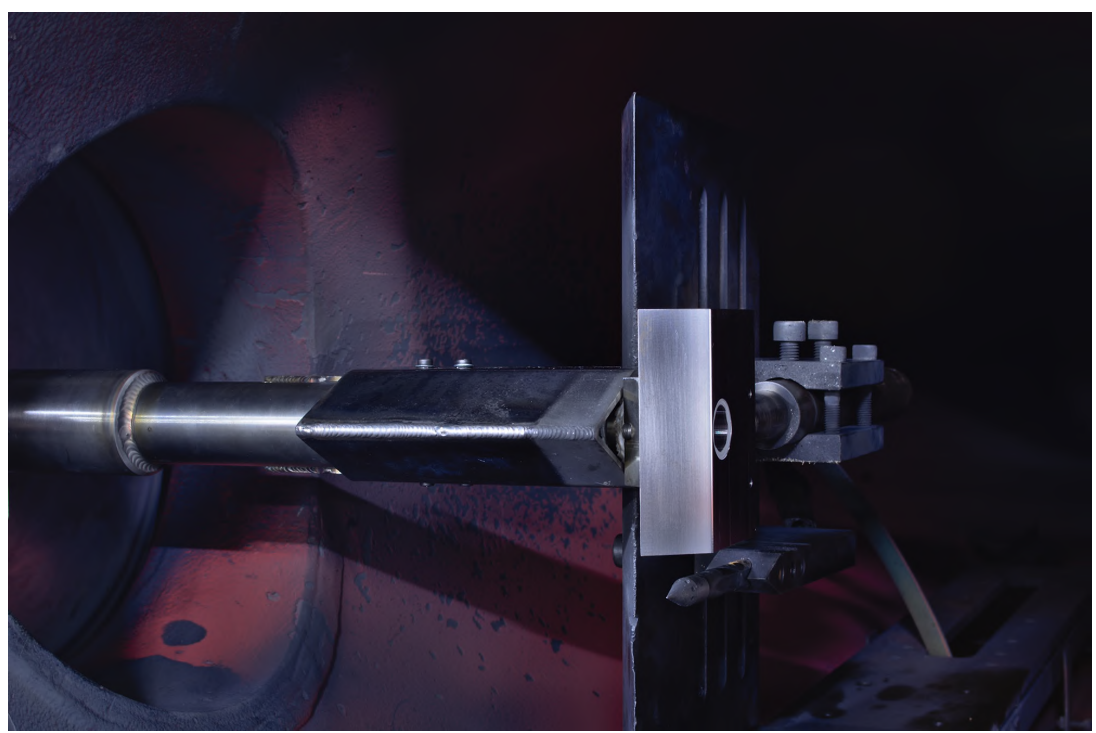




\section{Optics Layout}

- Filtered high speed imaging with a bandpass filter coupled to Shimadzu HPV-1 1MHz high speed camera (left)

- VUV emission spectroscopy system (right)

Shimadzu HPV-1 $1 \mathrm{MHz}$ High Speed Camera

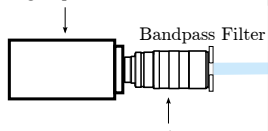

Nikkor Micro 200mm F/4D IF-ED

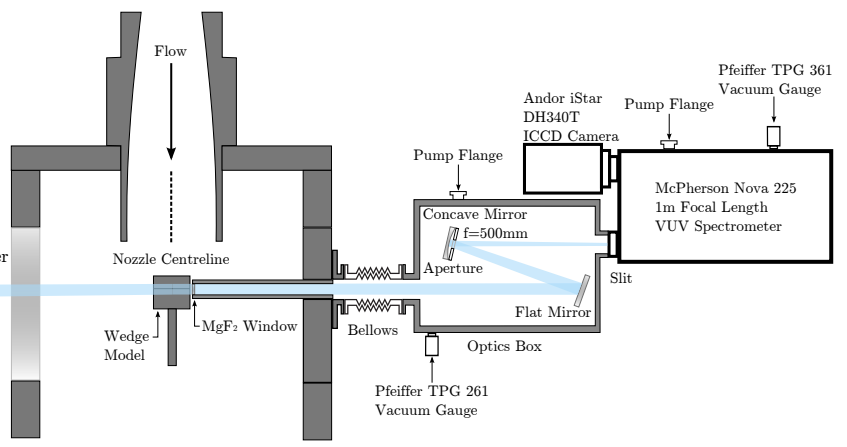




\section{Outline}

1 Introduction

2 Experimental Campaign

3 Numerical Simulation

4 Results and Analysis

- Flow Establishment

- VUV Spectra

5 Conclusions 


\section{Numerical Simulation}

- Flow Solver: Eilmer3 ${ }^{[8]}$

- Grid Generator: GridPro

- Radiation Modelling: NEQAIR V14 ${ }^{[9]}$

- Chemical Species: 11 species air including $\mathrm{N}, \mathrm{N}^{+}, \mathrm{NO}$, $\mathrm{NO}^{+}, \mathrm{N}_{2}, \mathrm{~N}_{2}^{+}, \mathrm{O}, \mathrm{O}^{+}, \mathrm{O}_{2}, \mathrm{O}_{2}^{+}$and $\mathrm{e}^{-}$

- Thermo-chemical model: Park's two temperature model and associated reaction rates ${ }^{[10]}$ with with rate controlling temperature defined as $T_{d}=T_{t r}^{0.7} T_{v e}^{0.3}$

[8] R. J. Gollan and P. A. Jacobs. "About the formulation, verification and validation of the hypersonic flow solver Eilmer". In: International Journal for Numerical Methods in Fluids 73.1 (Sept. 2013), pp. 19-57.

[9] Aaron Michael Brandis and Brett A Cruden. "NEQAIRv14. 0 Release Notes: Nonequilibrium and Equilibrium Radiative Transport Spectra Program". 2014.

[10] Chul Park. "Review of chemical-kinetic problems of future NASA missions. I - Earth entries". In: Journal of Thermophysics and Heat Transfer 7.3 (Sept. 1993), pp. 385-398. 


\section{Numerical Simulation}

Grid topology and boundary conditions

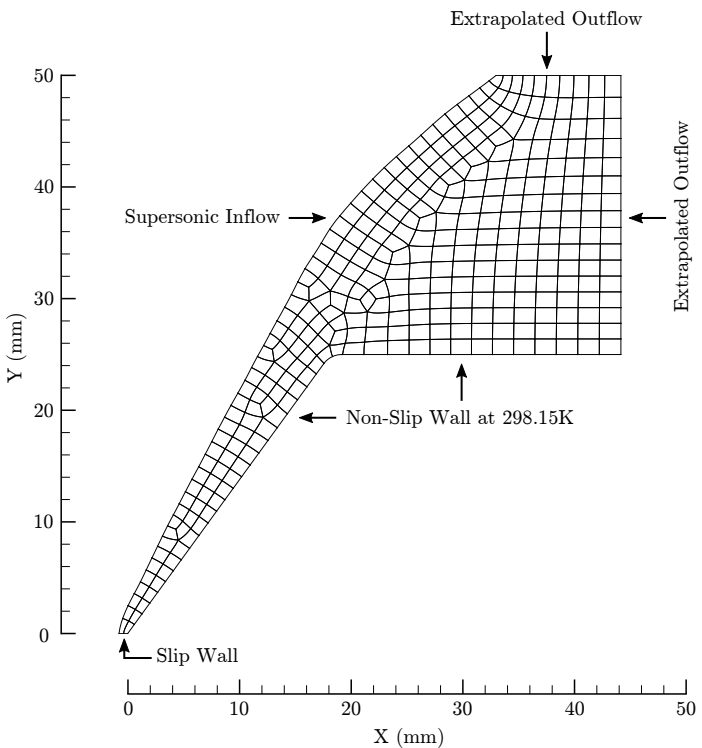




\section{Outline}

1 Introduction

2 Experimental Campaign

3 Numerical Simulation

4 Results and Analysis

- Flow Establishment

- VUV Spectra

5 Conclusions 


\section{Outline}

1 Introduction

2 Experimental Campaign

3 Numerical Simulation

4 Results and Analysis

- Flow Establishment

- VUV Spectra

5 Conclusions 


\section{Flow Establishment}

High speed video through Thorlabs FBH780-10 bandpass filter at $0.5 \mathrm{MHz}$ 


\section{Flow Establishment}

Synchronisation of under-model probe pressure, trigger signals and camera outputs

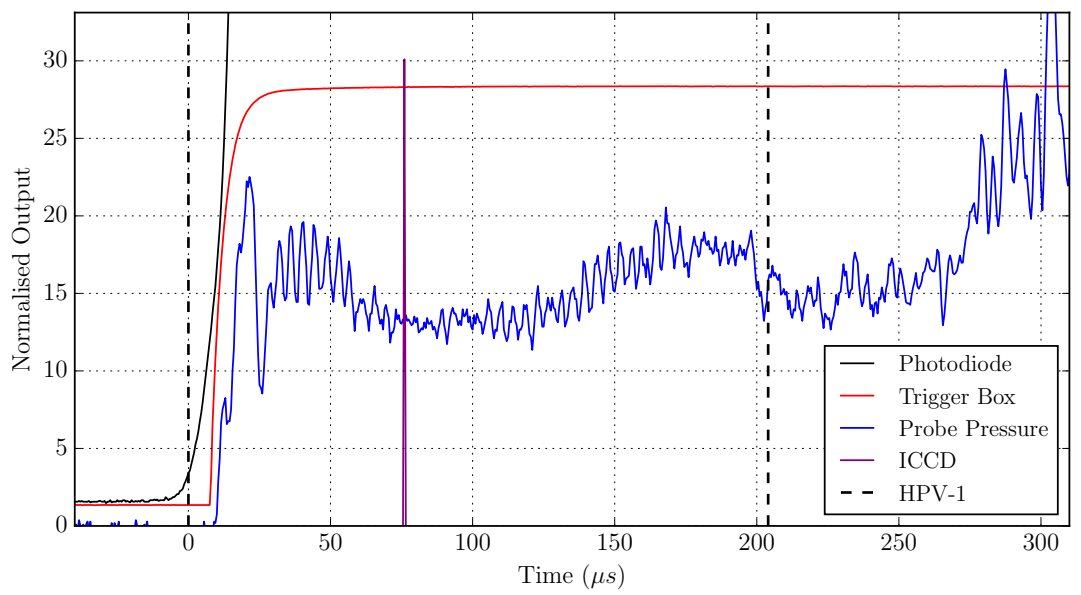




\section{Flow Steadiness}

Extracted pixel counts at $3.25 \mathrm{~mm}$ above wedge top for Shot x2s3022 with Condition 3

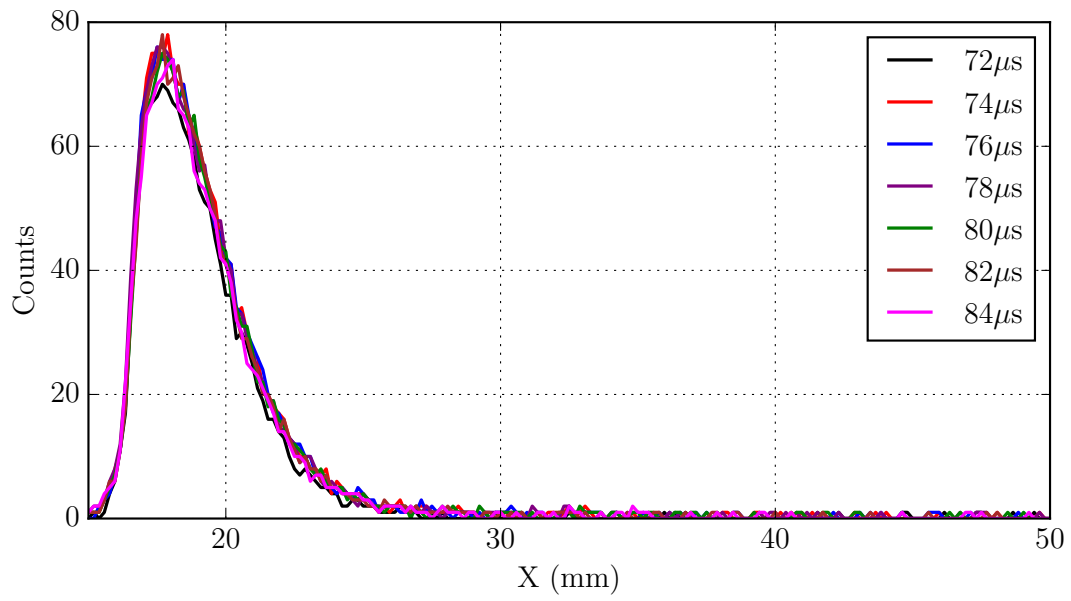




\section{Outline}

1 Introduction

2 Experimental Campaign

3 Numerical Simulation

4 Results and Analysis

- Flow Establishment

- VUV Spectra

5 Conclusions 


\section{VUV Spectra}

\section{Raw spectral image for Shot x2s3022 with Condition 3}

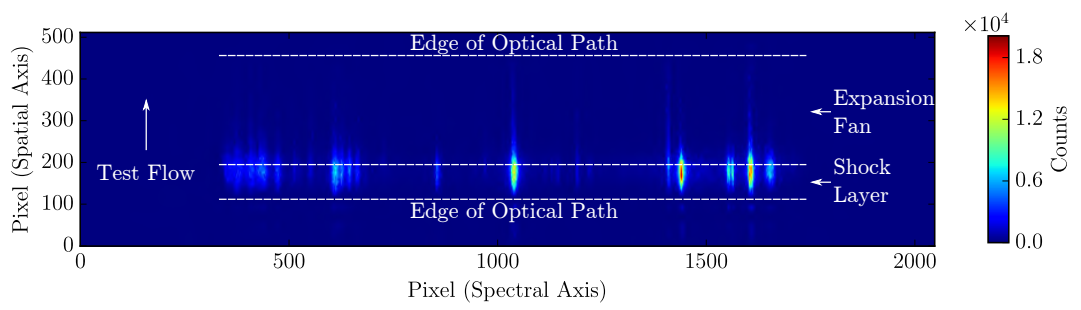




\section{Calibrated Spectra}

\section{Calibrated spectral image for Shot x2s3022 with Condition 3}
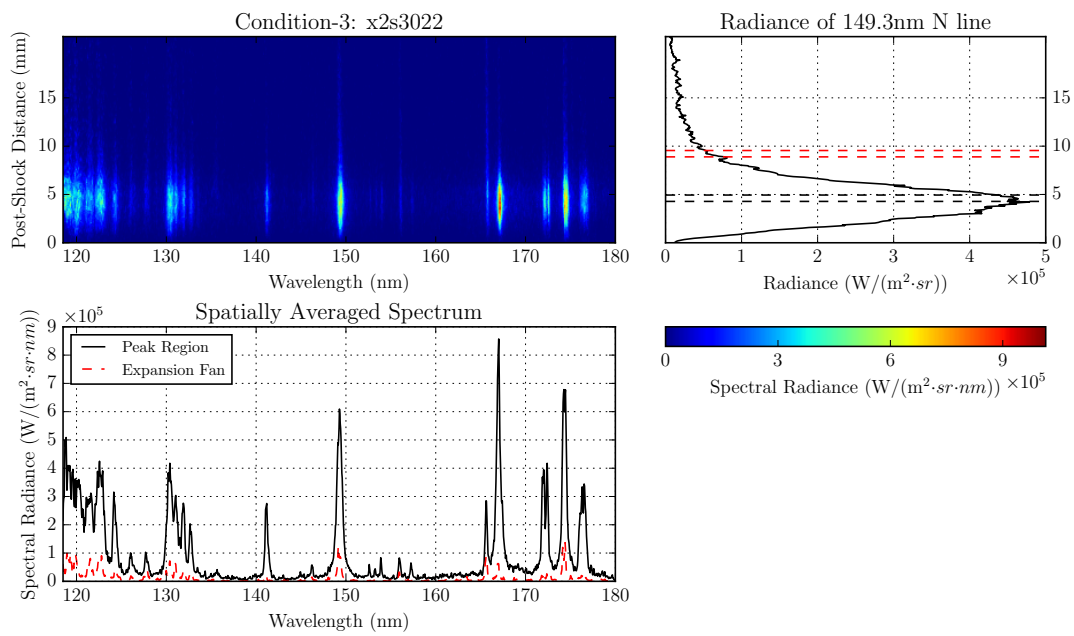


\section{Radiator Identification}

Shock layer radiators for Shot x2s3026 with Condition 1

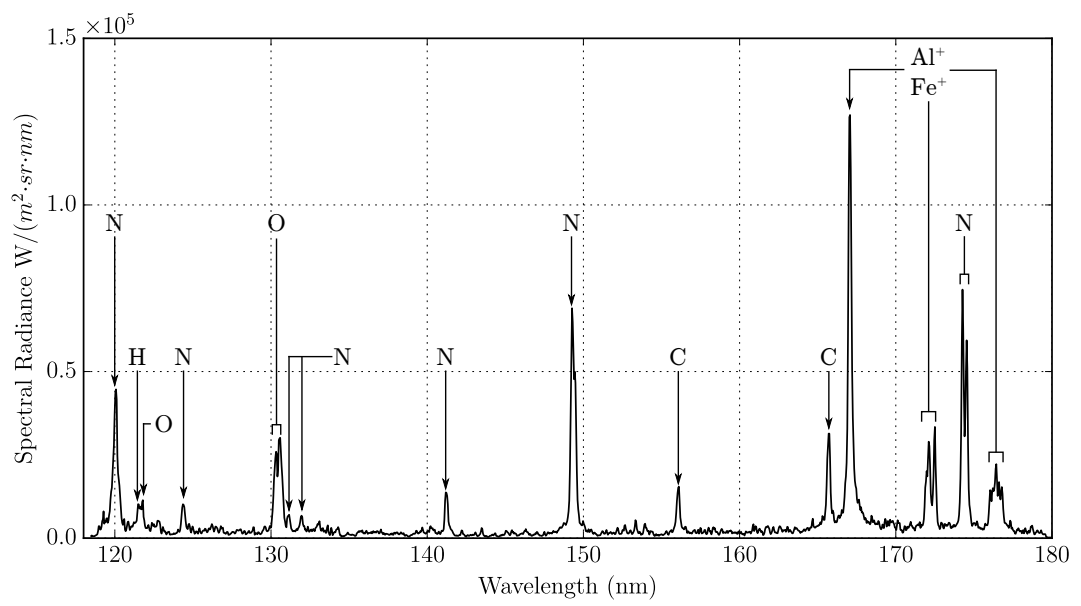




\section{Radiator Identification}

Expansion fan radiators for Shot x2s3026 with Condition 1

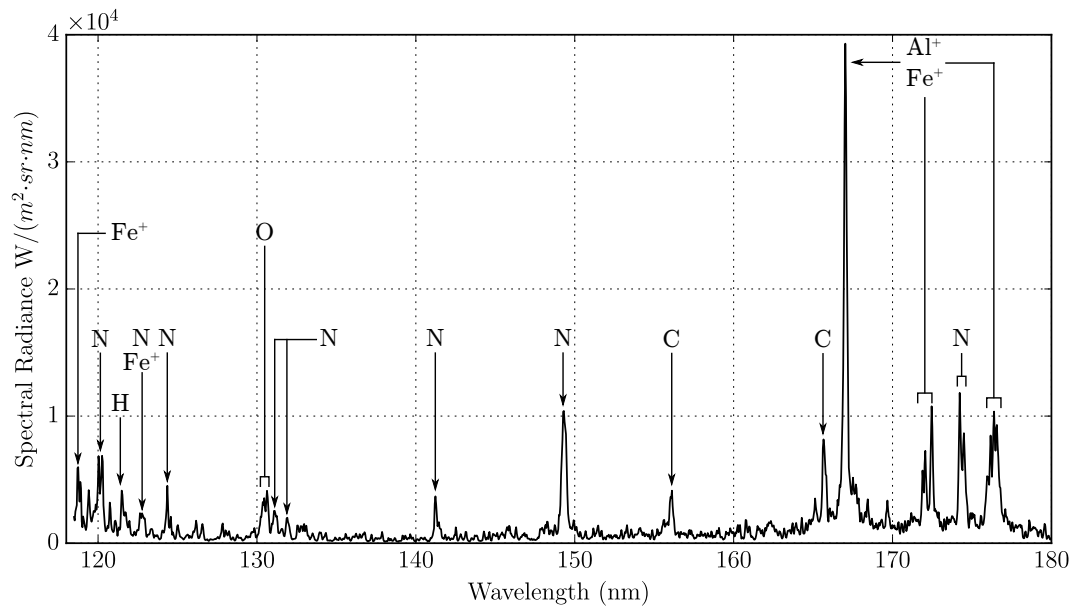




\section{Radiator Identification}

Shock layer radiators for Shot x2s3028 with Condition 2

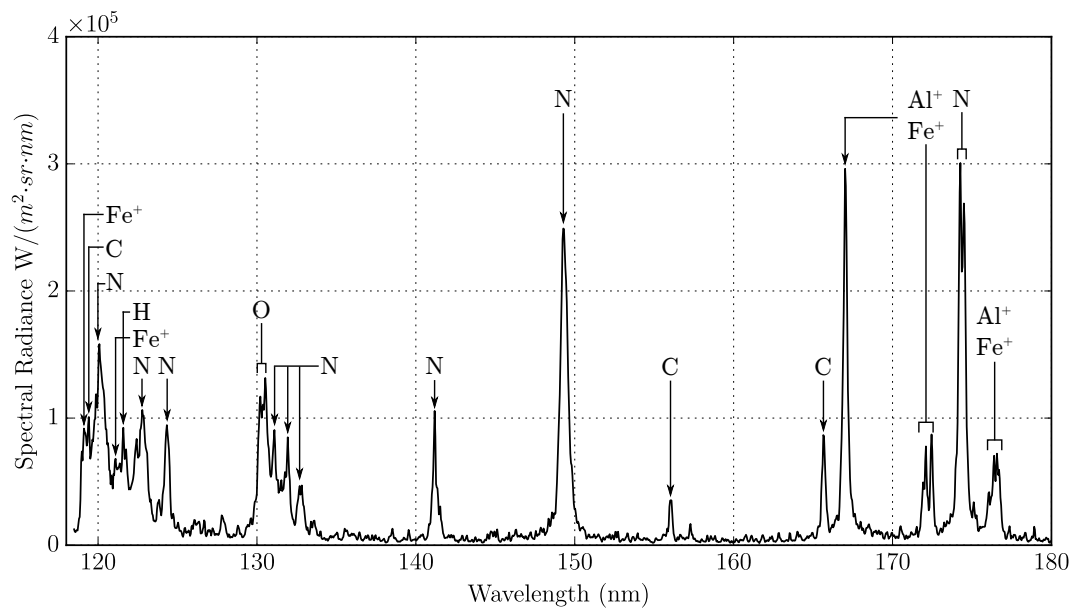




\section{Radiator Identification}

Expansion fan radiators for Shot x2s3028 with Condition 2

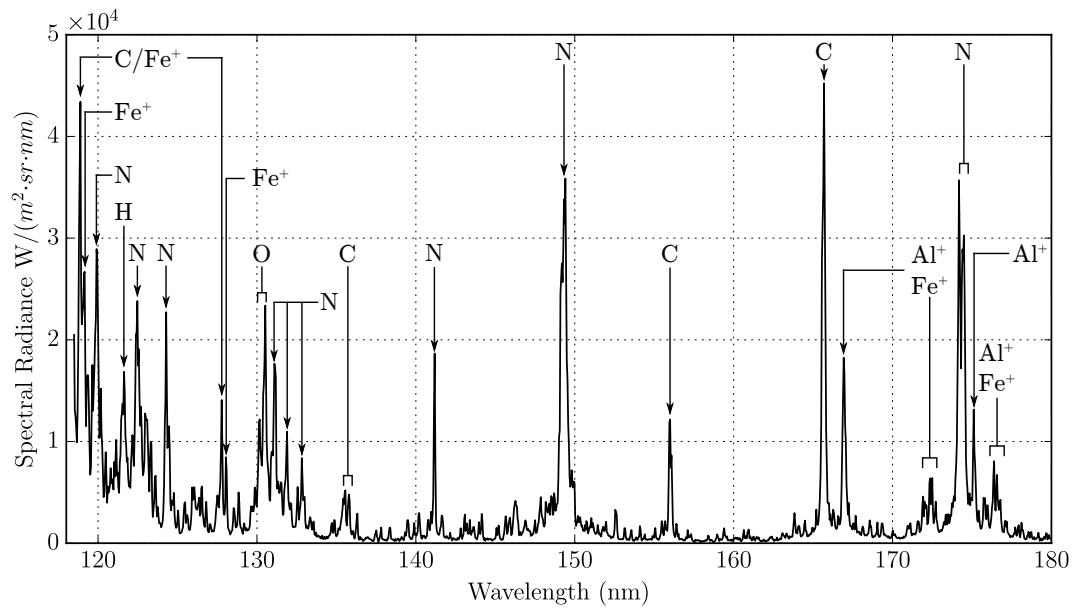




\section{Radiator Identification}

Shock layer radiators for Shot x2s3022 with Condition 3

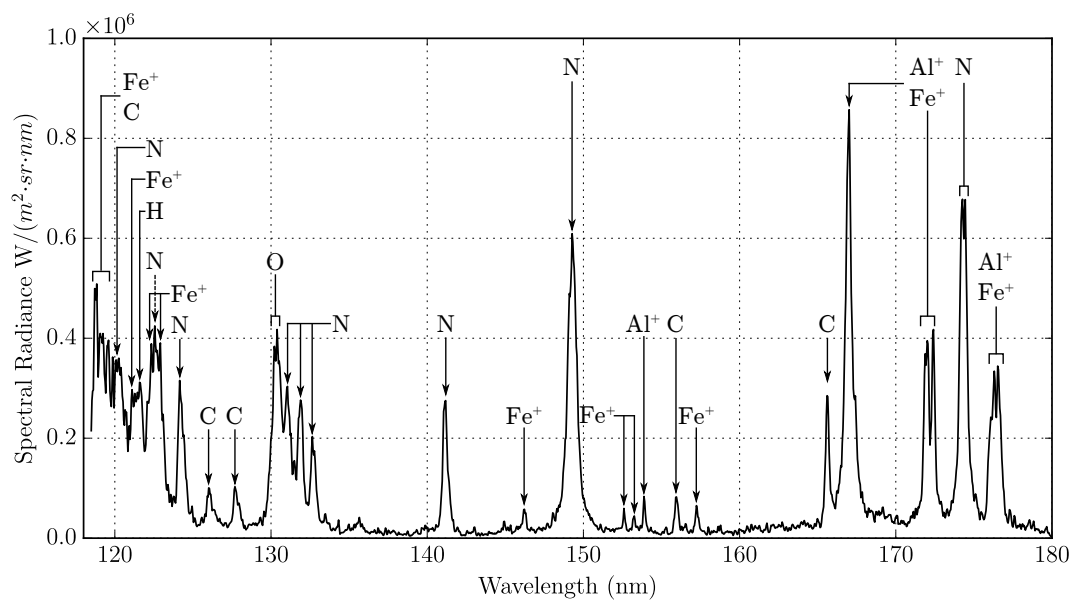




\section{Radiator Identification}

Expansion fan radiators for Shot x2s3022 with Condition 3

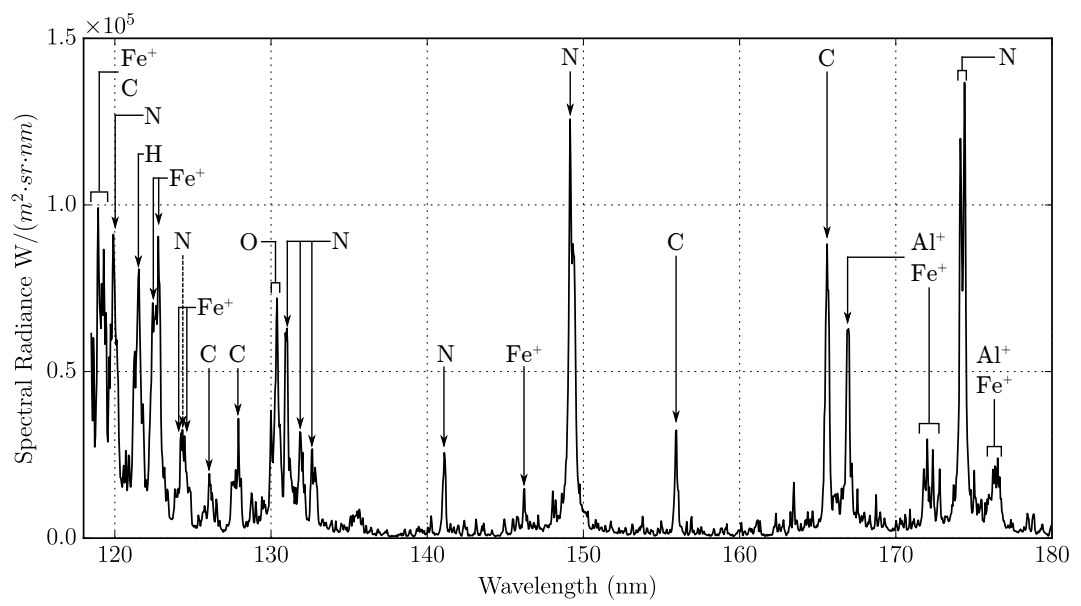


- The level of contamination increases with flow enthalpy

- The expansion fan spectra tend to be packed with more distinguishable features of contaminants

- $\mathrm{C}$ and $\mathrm{Al}^{+}$can be stronger relative to $\mathrm{N}$ lines in the expansion fan for certain conditions 


\section{Through-Wedge Spectra}

Through-wedge spectrum of Shot x2s3056 with Condition 1
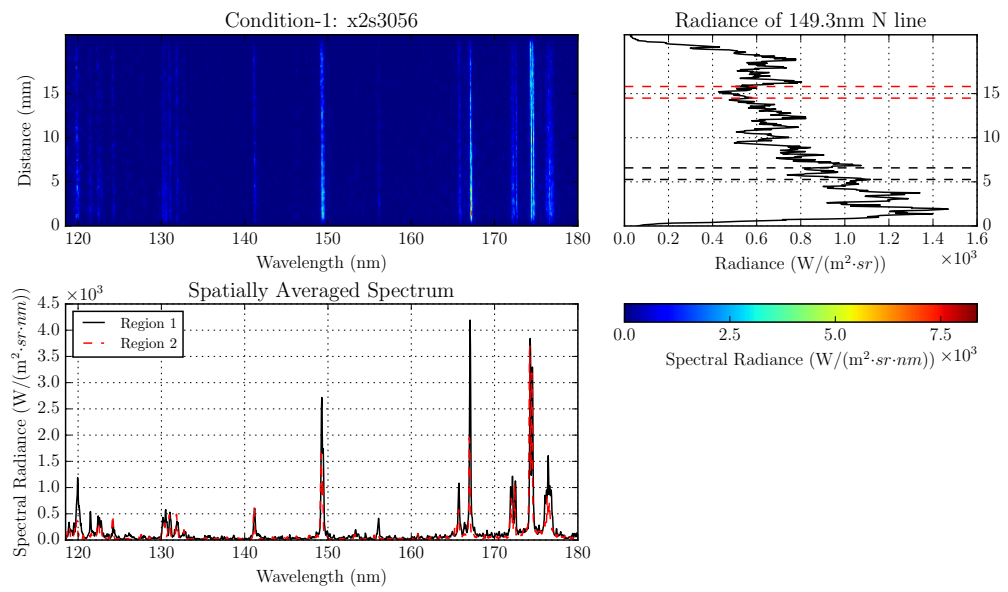


\section{Through-Wedge Spectra}

Through-wedge spectrum of Shot x2s3059 with Condition 2
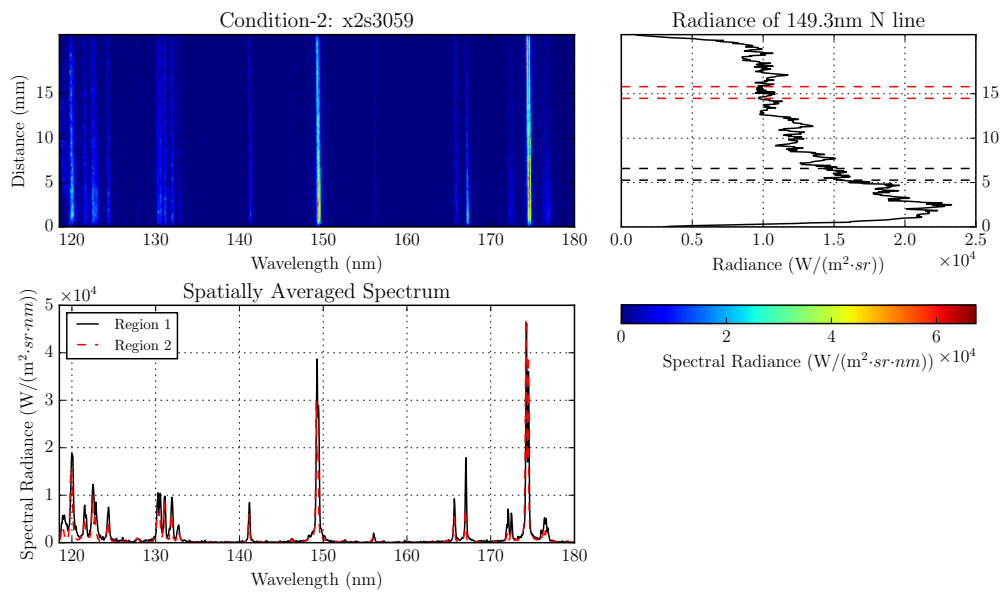


\section{Through-Wedge Spectra}

Through-wedge spectrum of Shot x2s3060 with Condition 3
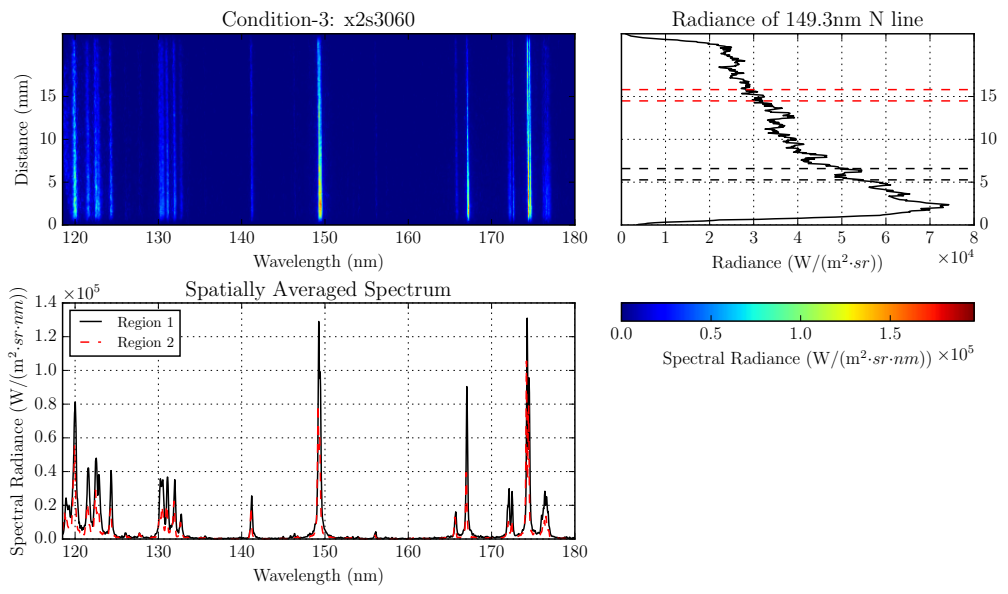


\section{VUV Spectra vs Simulations}

Radiance profiles of the $149 \mathrm{~nm} \mathrm{~N}$ line at 3.25, 5.75 and $8.25 \mathrm{~mm}$ above the top of the wedge compared between experiments and NEQAIR simulations for Condition 1

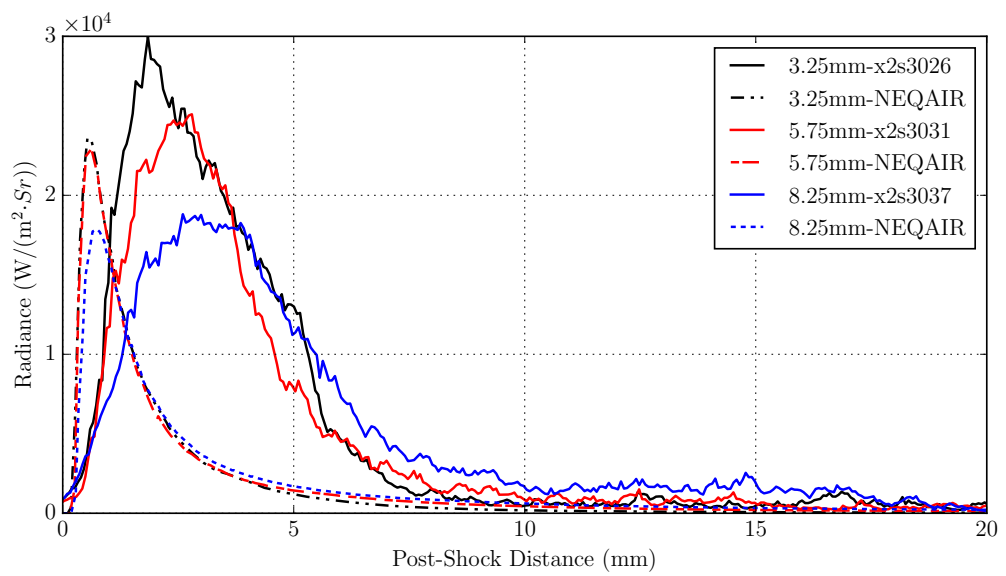




\section{VUV Spectra vs Simulations}

Radiance profiles of the $174 \mathrm{~nm} \mathrm{~N}$ line at 3.25, 5.75 and $8.25 \mathrm{~mm}$ above the top of the wedge compared between experiments and NEQAIR simulations for Condition 1

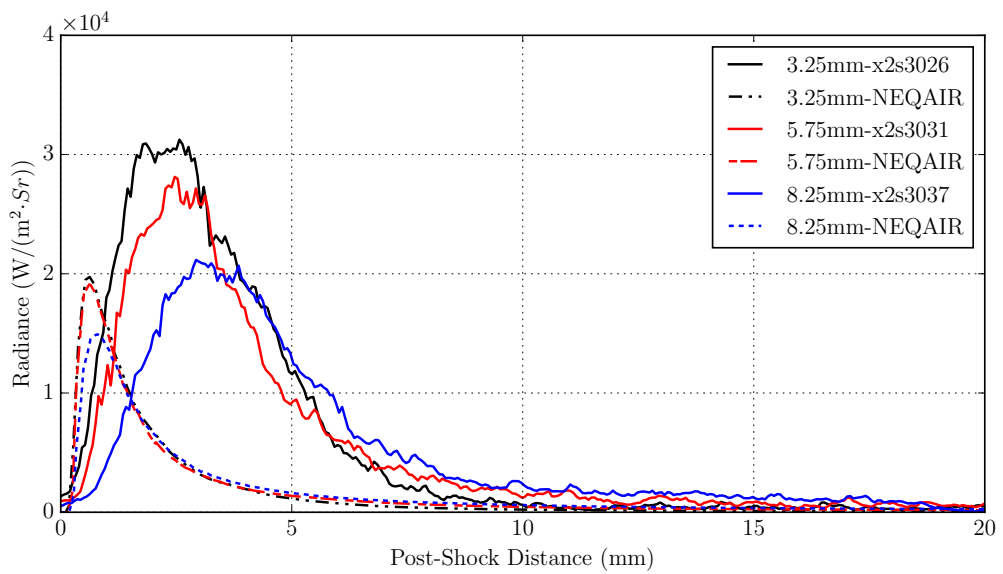




\section{VUV Spectra vs Simulations}

Experiment and NEQAIR results of the $149 \mathrm{~nm} \mathrm{~N}$ line, as well as selected flow variables along the line of sight at $8.25 \mathrm{~mm}$ above the top of the wedge for Condition 1

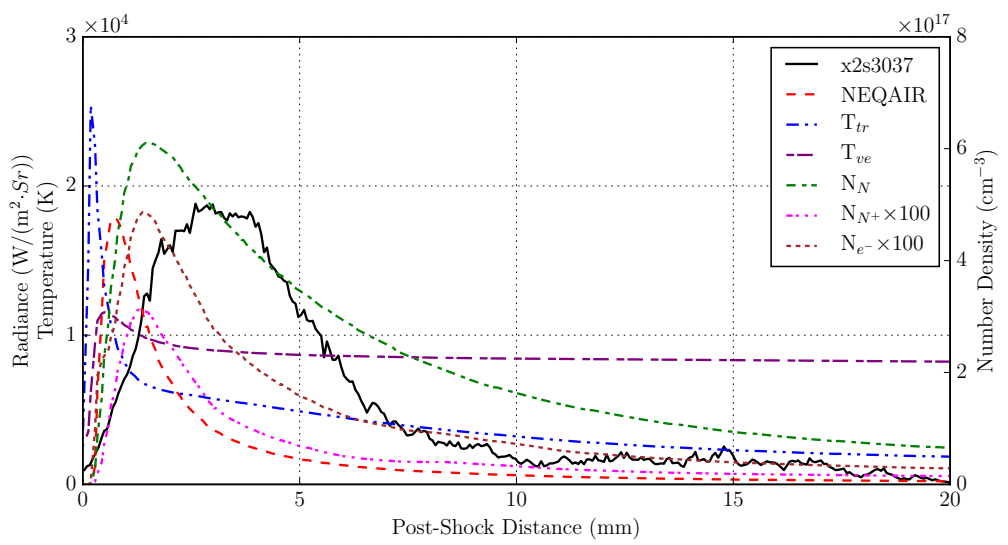




\section{VUV Spectra vs Simulations}

Experiment and NEQAIR results of the $149 \mathrm{~nm} \mathrm{~N}$ line, as well as selected flow variables along the line of sight at $8.25 \mathrm{~mm}$ above the top of the wedge for Condition 1

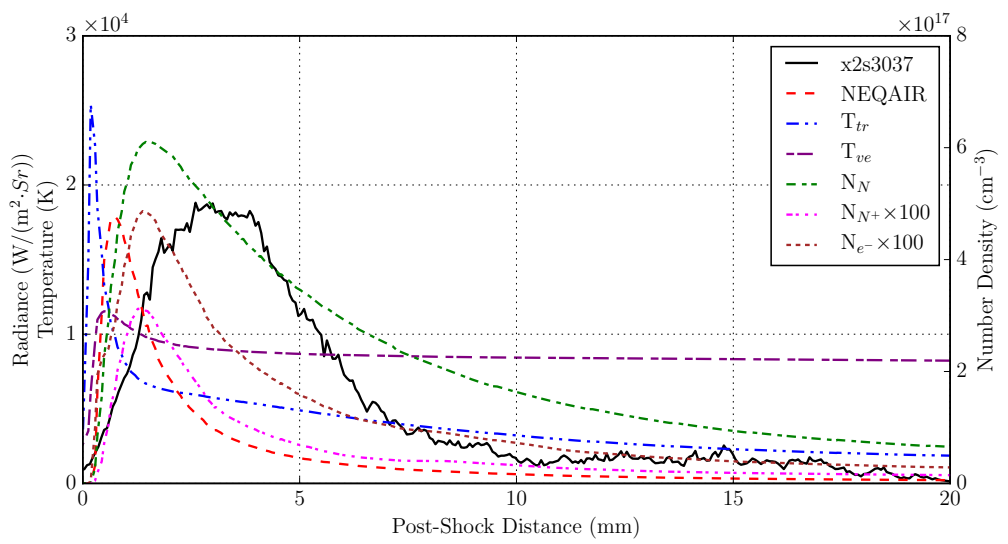




\section{VUV Spectra vs Simulations}

Density and selected species mass fraction distributions along the line of sight at $8.25 \mathrm{~mm}$ above the top of the wedge for Condition 1

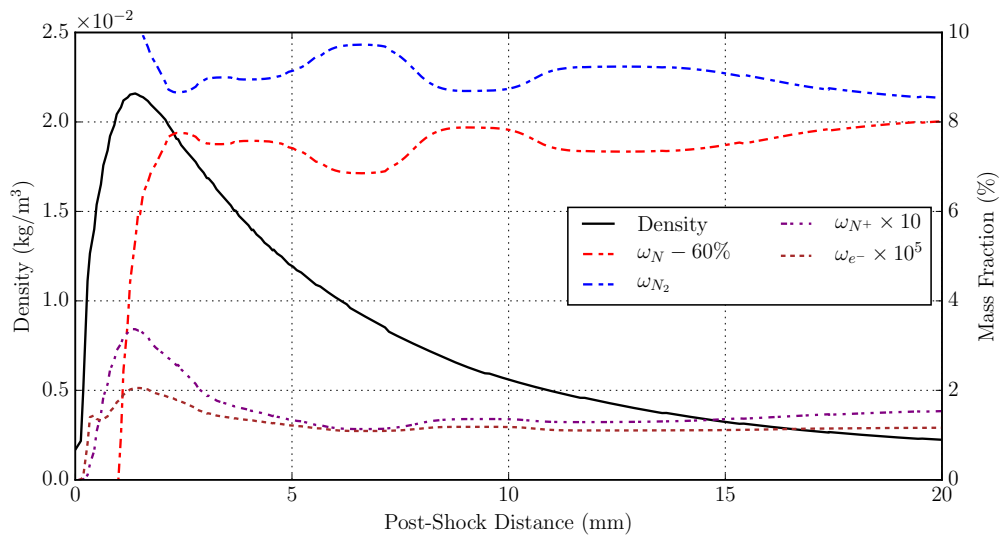




\section{VUV Spectra vs Simulations}

Radiance profiles of the $149 \mathrm{~nm} \mathrm{~N}$ line at 3.25, 5.75 and $8.25 \mathrm{~mm}$ above the top of the wedge compared between experiments and NEQAIR simulations for Condition 2

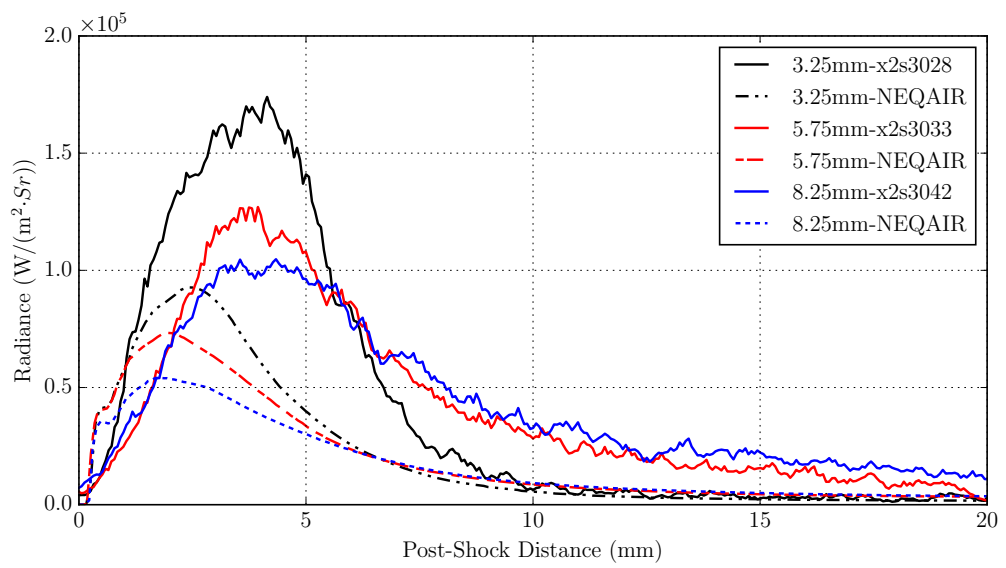




\section{VUV Spectra vs Simulations}

Experiment and NEQAIR results of the $149 \mathrm{~nm} \mathrm{~N}$ line, as well as selected flow variables along the line of sight at $8.25 \mathrm{~mm}$ above the top of the wedge for Condition 2

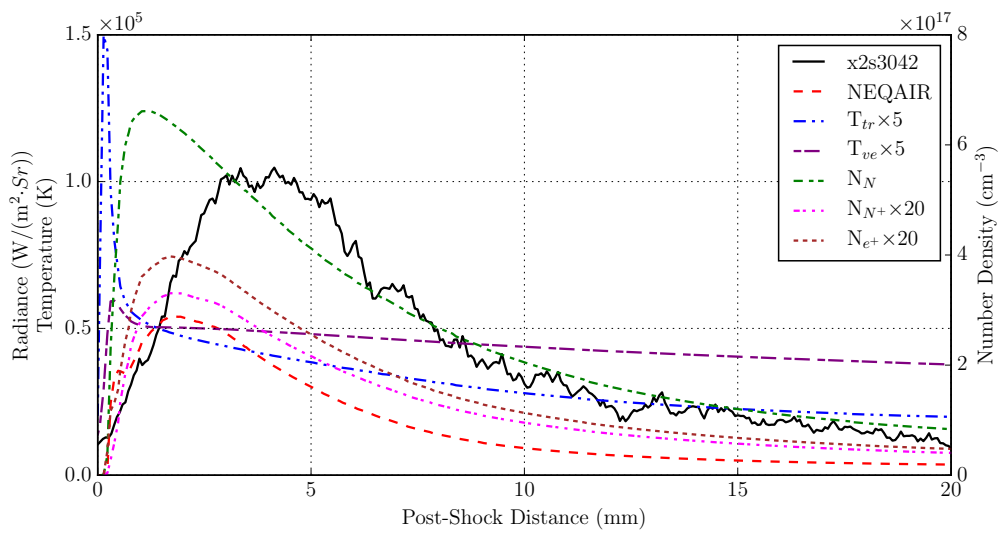




\section{VUV Spectra vs Simulations}

Density and selected species mass fraction distributions along the line of sight at $8.25 \mathrm{~mm}$ above the top of the wedge for Condition 2

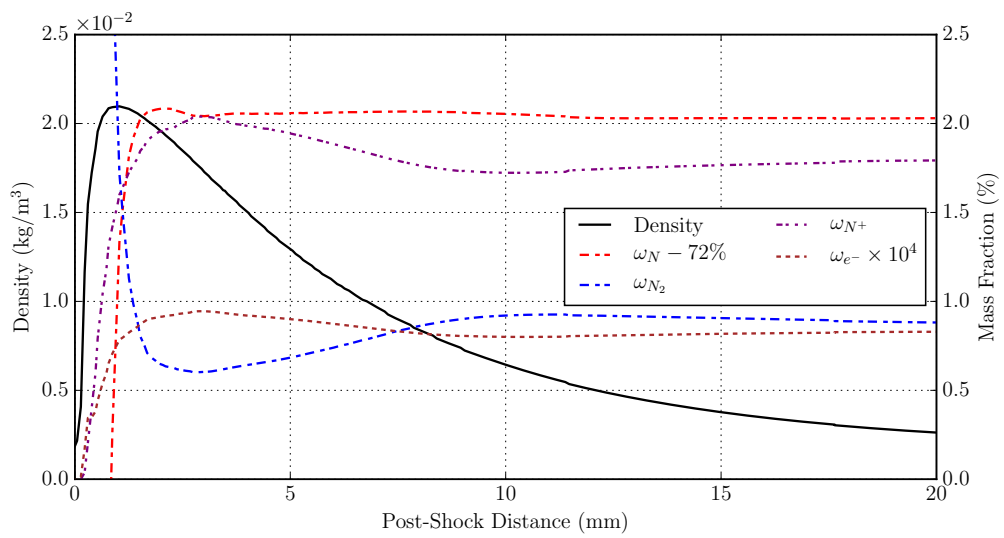




\section{VUV Spectra vs Simulations}

Radiance profiles of the $149 \mathrm{~nm} \mathrm{~N}$ line at 3.25, 5.75 and $8.25 \mathrm{~mm}$ above the top of the wedge compared between experiments and NEQAIR simulations for Condition 3

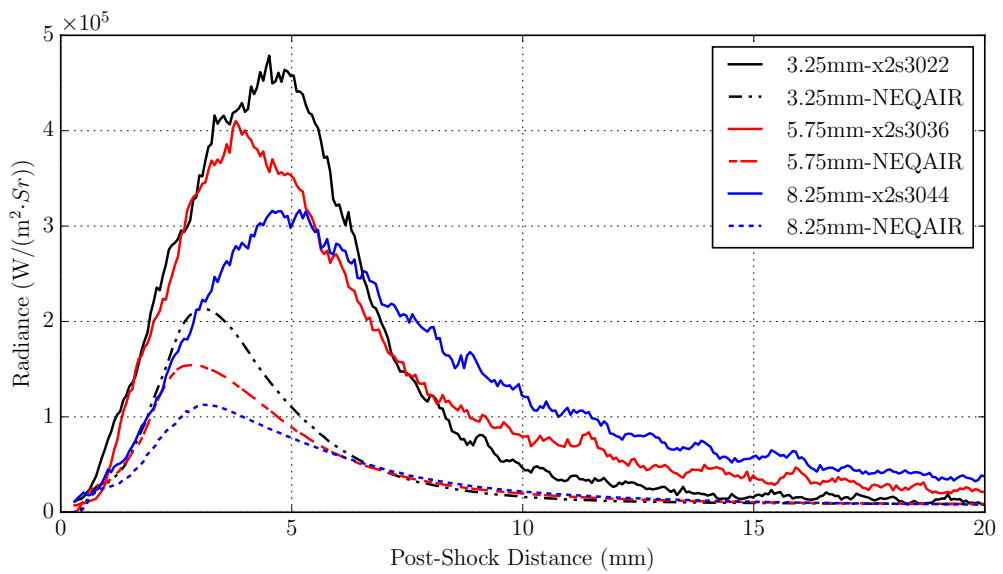




\section{VUV Spectra vs Simulations}

Experiment and NEQAIR results of the $149 \mathrm{~nm} \mathrm{~N}$ line, as well as selected flow variables along the line of sight at $8.25 \mathrm{~mm}$ above the top of the wedge for Condition 3

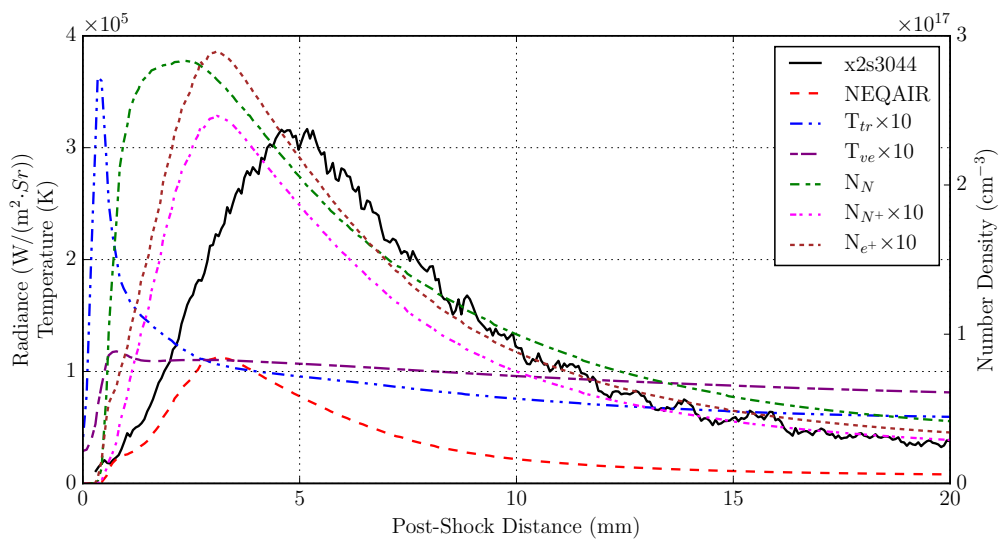




\section{VUV Spectra vs Simulations}

Density and selected species mass fraction distributions along the line of sight at $8.25 \mathrm{~mm}$ above the top of the wedge for Condition 3

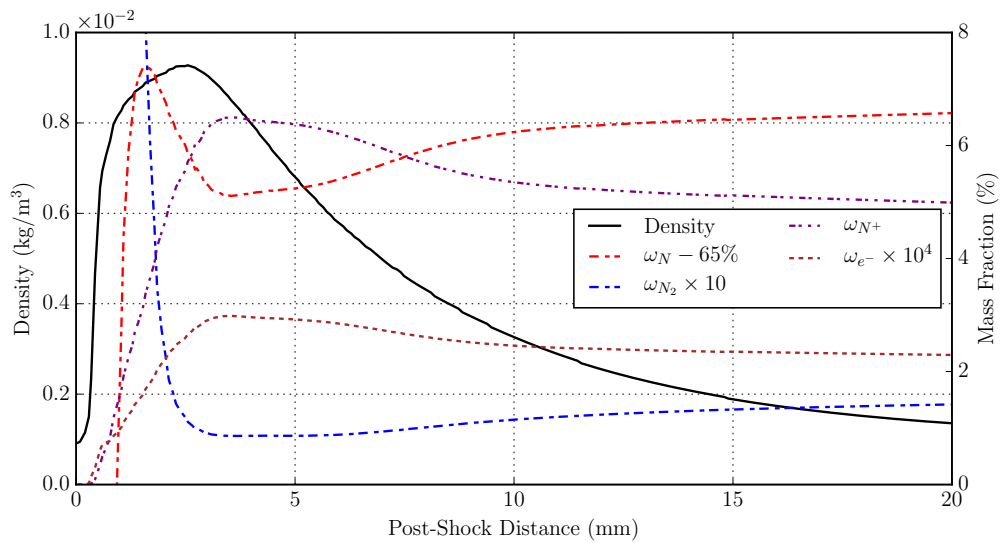




\section{Filtered Images vs Simulations}

Radiance profiles of the $777 \mathrm{~nm}$ oxygen triplet at 3.25, 5.75 and $8.25 \mathrm{~mm}$ above the top of the wedge compared between experiments and NEQAIR simulations for Condition 2

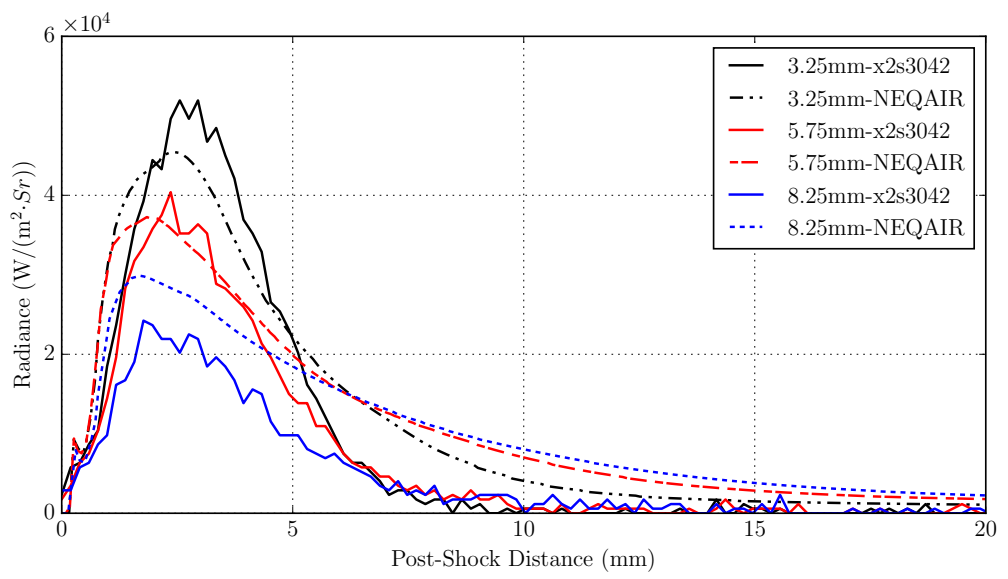




\section{Filtered Images vs Simulations}

Density and selected species mass fraction distributions along the line of sight at $8.25 \mathrm{~mm}$ above the top of the wedge for Condition 2

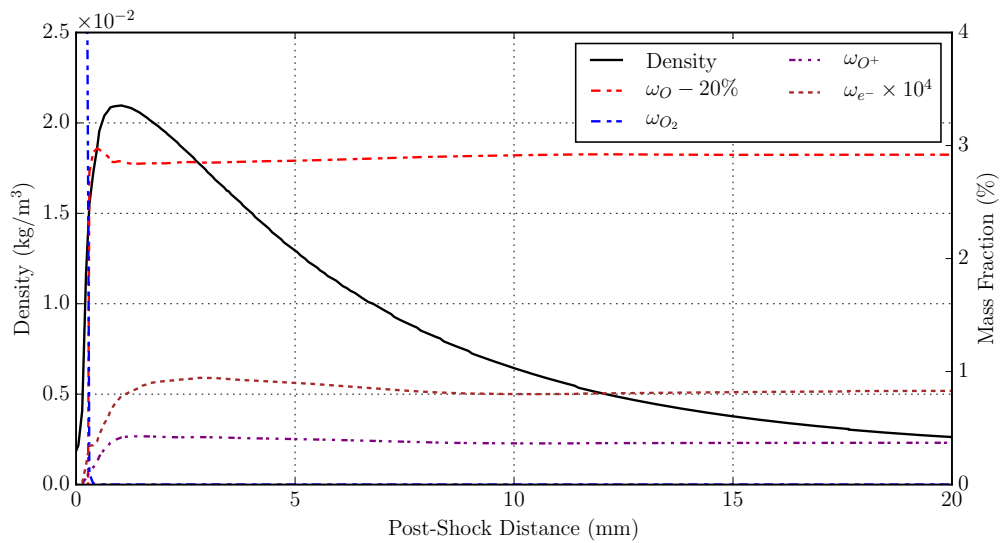




\section{Filtered Images vs Simulations}

Radiance profiles of the $777 \mathrm{~nm}$ oxygen triplet at 3.25, 5.75 and $8.25 \mathrm{~mm}$ above the top of the wedge compared between experiments and NEQAIR simulations for Condition 3

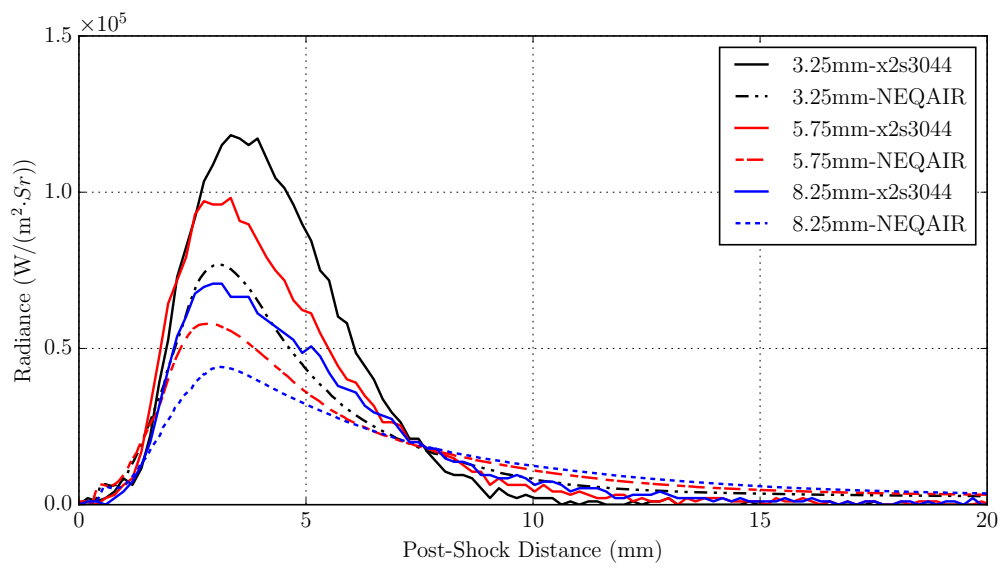




\section{Filtered Images vs Simulations}

Density and selected species mass fraction distributions along the line of sight at $8.25 \mathrm{~mm}$ above the top of the wedge for Condition 3

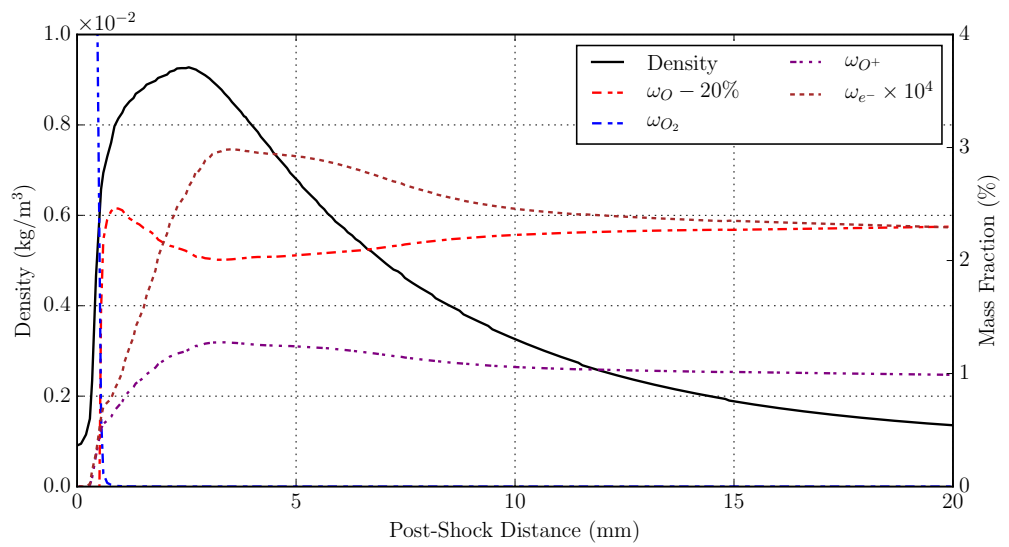




\section{Outline}

1 Introduction

2 Experimental Campaign

3 Numerical Simulation

4 Results and Analysis

- Flow Establishment

- VUV Spectra

5 Conclusions 
- The spatial profiles of 149 and $174 \mathrm{~nm} \mathrm{~N}$ radiance are in general of larger spans than those predicted by NEQAIR

- For Conditions 2 and 3, the peak radiance levels are significantly underestimated. Large departures of predicted radiance values from experiment appear to occur at the start of the expansion fan where the electron-ion recombination process commences

- NEQAIR results agree well with the filtered images of $777 \mathrm{~nm}$ oxygen triplet in the compression region and at the start of the expansion fan for Condition 2. For Condition 3 , radiance in the compression region and at the start of the expansion fan are underpredicted by as much as $40 \%$, but the afterbody radiance is overpredicted by up to $100 \%$ 


\section{Many Thanks}

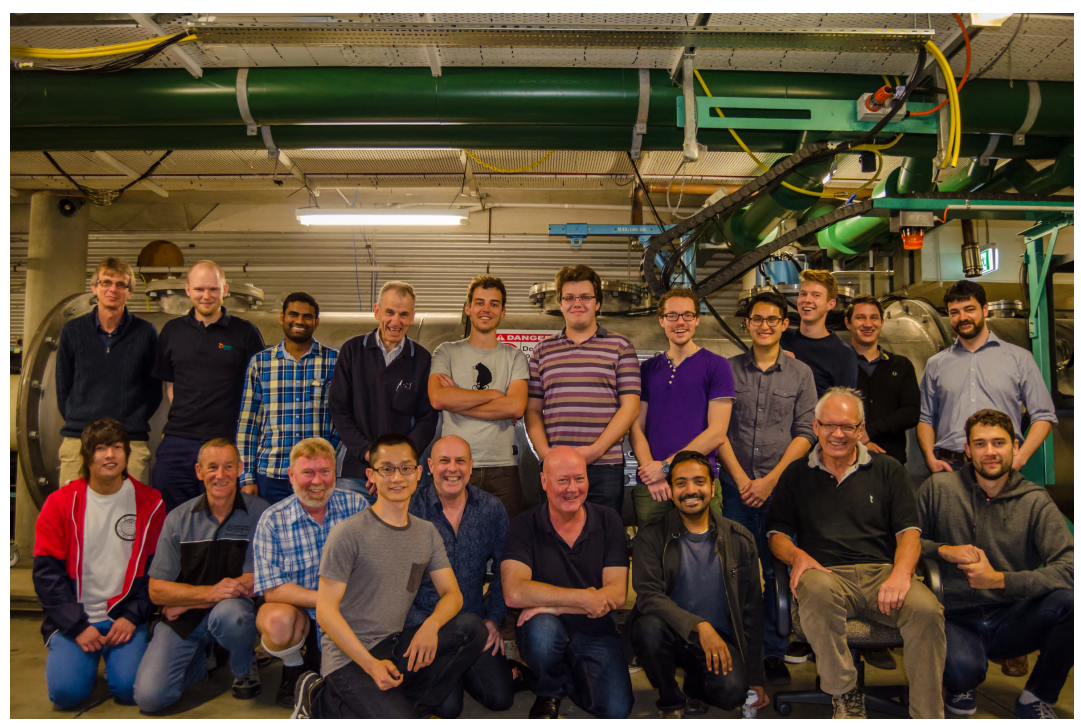




\section{Any Questions?}

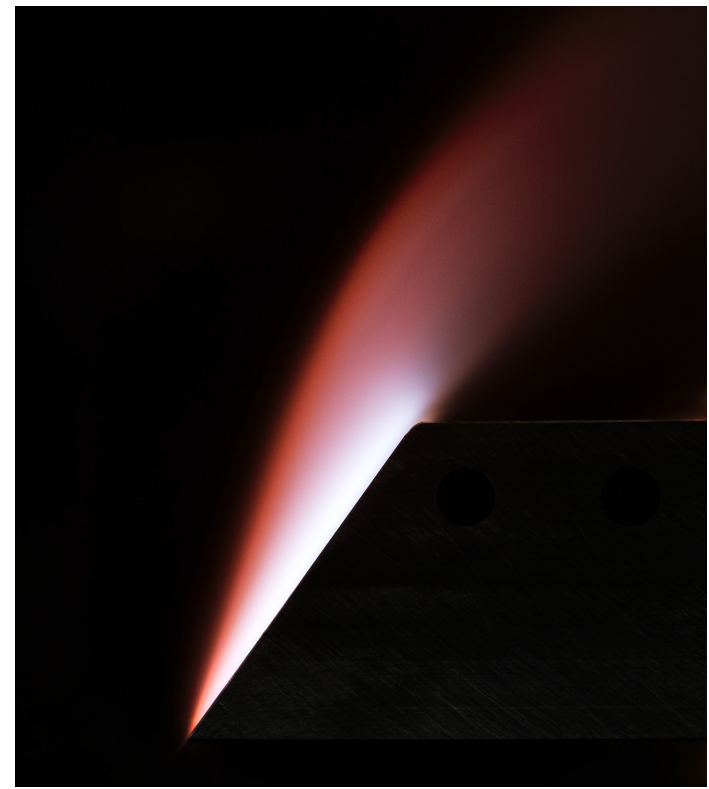

